\title{
Genetic disruption of calpain-1 and calpain-2 attenuates tumorigenesis in mouse models of HER2+ breast cancer and sensitizes cancer cells to doxorubicin and lapatinib
}

\author{
James A. MacLeod ${ }^{1,2}$, Yan Gao $^{2}$, Christine Hall', William J. Muller ${ }^{3}$, Taranjit S. \\ Gujral $^{4}$ and Peter A. Greer ${ }^{1,2}$ \\ ${ }^{1}$ Department of Pathology and Molecular Medicine, Queen's University, Kingston, Ontario, Canada \\ ${ }^{2}$ Division of Cancer Biology and Genetics, Queen's Cancer Research Institute, Kingston, Ontario, Canada \\ ${ }^{3}$ Rosalind and Morris Goodman Cancer Centre, Department of Biochemistry, McGill University, Montreal, Quebec, Canada \\ ${ }^{4}$ Division of Human Biology, Fred Hutchinson Cancer Research Center, Seattle, WA, USA \\ Correspondence to: Peter A. Greer, email: greerp@queensu.ca \\ Keywords: calpain; capns 1; breast cancer; HER2 \\ Received: July 22, $2018 \quad$ Accepted: August 23, $2018 \quad$ Published: September 07, 2018 \\ Copyright: MacLeod et al. This is an open-access article distributed under the terms of the Creative Commons Attribution License \\ 3.0 (CC BY 3.0), which permits unrestricted use, distribution, and reproduction in any medium, provided the original author and \\ source are credited.
}

\section{ABSTRACT}

Calpains are a family of calcium activated cysteine proteases which participate in a wide range of cellular functions including migration, invasion, autophagy, programmed cell death, and gene expression. Calpain-1 and calpain-2 isoforms are ubiquitously expressed heterodimers composed of isoform specific catalytic subunits coupled with an obligate common regulatory subunit encoded by capns1. Here, we report that conditional deletion of capns 1 disrupted calpain-1 and calpain-2 expression and activity, and this was associated with delayed tumorigenesis and altered signaling in a transgenic mouse model of spontaneous HER2 ${ }^{+}$breast cancer and effectively blocked tumorigenesis in an orthotopic engraftment model. Furthermore, capns1 knockout in a tumor derived cell line correlated with enhanced sensitivity to the chemotherapeutic doxorubicin and the HER2/EGFR tyrosine kinase inhibitor lapatinib. Collectively, these results indicate pro-tumorigenic roles for calpains-1/2 in HER2+ breast cancer and provide evidence that calpain-1/2 inhibitors could have anti-tumor effects if used either alone or in combination with chemotherapeutics and targeted agents.

\section{INTRODUCTION}

Calpains are a family of 15 calcium-dependent intracellular thiol proteases which are involved in a wide range of cellular and physiological functions (reviewed in [1-3]). Aberrant expression or activity of calpains is implicated in the etiology of several diseases including diabetes, Alzheimer's and cancer; this has stimulated considerable interest in the development and preclinical testing of calpain inhibitors (reviewed in [4]); however, to date there are none approved for clinical use. Calpain-1 and calpain-2, the most widely studied members of this family, are ubiquitously expressed heterodimers composed of isoform specific catalytic subunits encoded by capn 1 or capn2, respectively, coupled with an obligate common regulatory subunit encoded by capns 1 . Genetic disruption of capns 1 is associated with destabilization of the CAPN1 and CAPN2 catalytic subunits and loss of calpain-1 and calpain-2 activities in vivo $[5,6]$.

Hundreds of calpain substrates have been described [7], and the effect of calpain cleavage on their functions (where studied) varies from activation to inactivation and often involves changes in subcellular localization or protein-protein associations. Since many of these substrates are components of key cell signaling pathways, calpains can have pleomorphic effects on cellular behavior, depending upon cell type, substrate expression and the context in which calpain is activated. Many of 
the pathways calpain activity impinges upon are related to tumorigenesis (reviewed in [8]), including key survival and apoptosis pathways such as the PI3K-AKT pathway [9-11], cell cycle checkpoints [12-14], migration and invasion [15-18], as well as the function of oncoproteins such as HER2 [19] and MYC [20]. As calpain function is implicated in diverse signaling networks, perhaps unsurprisingly, there is evidence that calpain may engage in opposing roles; for example, promoting apoptosis in response to challenge with etoposide or camptothecin, and protecting the cell from cytotoxic responses to tumor necrosis factor $\alpha$ or staurosporine [11].

Translational studies have revealed that high calpain-2 expression correlates with adverse outcomes in basal-like or triple-negative breast cancer [21], while high calpain-1 expression correlated with poor relapsefree survival in HER2 ${ }^{+}$breast cancer [22]. High calpain-2 levels were also associated with platinum resistance and poor overall survival in ovarian cancer patients [23].

In vitro studies have linked calpain to trastuzumab resistance in $\mathrm{HER} 2^{+}$breast cancer cells through generation of a p95HER2 fragment [19, 24], or resistance to chemotherapeutics like doxorubicin through regulating multidrug resistance protein function [25]. Thus, a growing body of research suggests that inhibition of calpain may suppress tumorigenesis and could cooperate or synergize with specific existing treatments to improve breast cancer patient outcomes.

In this study we use genetic manipulation of capns 1 in HER2 ${ }^{+}$models of breast cancer to show that calpain-1 and/or calpain- 2 are involved in but not required for spontaneous tumor formation in a transgenic mouse model of HER2/NEU-driven tumorigenesis; however, capns 1 knockout in established carcinoma cells effectively blocked their tumor forming capability in an orthotopic engraftment model and enhanced in vitro sensitivity to doxorubicin and lapatinib.

\section{RESULTS}

\section{Deletion of capns1 delays HER2/NEU-induced tumorigenesis}

The stability and activity of calpain-1 and calpain-2 are contingent upon expression of the common regulatory subunit encoded by capns 1 [26, 27], and capns 1 knockout in transgenic mice has been shown to abolish both calpain-1 and calpain-2 [5, 6]. To test the potential involvement of calpain- 1 and calpain- 2 in HER2-driven mammary tumorigenesis, we crossed the NIC transgenic mouse model [28] with conditionally targeted (floxed) capns1 mice [6]. Co-expression of oncogenic HER2/NEU and the CRE recombinase from the NIC transgene in the mammary epithelium resulted in deletion of floxed capns 1 alleles and ablation of CAPNS1 expression in mammary tumors arising in
NIC capns $1^{\text {floxflox }}(\mathrm{KO})$ mice, while tumors from NIC capns $1^{+/+}$(WT) mice retained CAPNS1 expression (Supplementary Figure 1). Deletion of capns 1 in the mammary epithelium correlated with a significant delay in spontaneous tumor onset (median time $\mathrm{KO}=318$ vs $\mathrm{WT}=300$ days; $p=0.0277)$; and $10 \%$ of $\mathrm{KO}$ mice remained tumor-free beyond 600 days of age while nearly all WT mice had developed tumors by this age (Figure 1). While these data show that calpain-1 and calpain-2 are not necessary for HER2/NEU-driven tumorigenesis, they indicate that one or both calpains contribute to carcinogenesis.

To assess possible calpain-mediated signaling pathways that underpin this delay, an RPPA analysis was performed on tumor lysates using 128 antibodies, predominantly directed against phosphopeptides in important signaling nodes $[29,30]$. This analysis revealed five proteins (EGFR, JNK, STAT1, MARCKS and GSK3 $\beta$ ) which were differentially phosphorylated in WT and $\mathrm{KO}$ tumors (Figure 2).

\section{Establishment of a conditional capns1 knockout HER2/NEU-driven mammary tumor epithelial cell line}

To further study the involvement of calpains-1/2 in HER2/NEU-driven tumorigenesis we next established a conditional capns 1 knockout mammary carcinoma cell line model. Floxed capns 1 mice were crossed with $n e u^{N T}$ transgenic mice [31], which express oncogenic HER2/NEU in the mammary epithelium under the control of the MMTV LTR. A tumor arising in a $n e u^{N T}$ capns $1^{\text {flox flox }}$ female mouse was used to derive a mammary tumor epithelial cell (MTEC) line. To create isogenic MTECs without or with calpain-1/2 activity, capns $1^{\text {flox flox }}$ MTECs were transduced with retroviruses encoding either CRE-recombinase (KO) or the empty vector (WT), respectively. The retrovirus also encoded puromycin phosphotransferase, which enabled selection of transduced cell populations. Immunoblotting of the puromycin selected populations revealed the expected loss of CAPNS1 protein expression in CRE-transduced cells, and casein zymography showed the loss of both calpain-1/2 activities (Figure 3). Mouse embryonic fibroblasts (MEFs) generated from capns $1^{+/+}$(WT) and capns $1^{-/}$(KO) embryos served as controls in this analysis [6]. MTECs express predominantly calpain-2, with only trace amounts of calpain-1.

\section{Capns1 deletion in MTECs did not affect in vitro migration but did attenuate in vitro invasion}

Calpains-1/2 have been implicated in membranecytoskeletal dynamics associated with cell migration and invasion $[18,32]$. In vitro migration and invasion were both compromised by capns $1 \mathrm{KO}$ in mouse embryonic 
fibroblasts $[15,17]$ or capns1 knockdown in MDAMB-231 breast cancer cells [25]; and capn2 knockdown was associated with dysregulated focal adhesion turnover [18] and lamellipodia dynamics [16] in fibroblasts, as well as attenuated migration and invasion in mammary carcinoma cells [9].
Surprisingly, capns1 KO MTECs did not display a migration defect in a wound healing assay (Figure 4A). However, when the invasive ability of MTECs was assessed using matrigel-coated transwell Boyden chamber assays, capns $1 \mathrm{KO}$ correlated with attenuated cell invasion activity (Figure 4B, $p=0.006$ ).

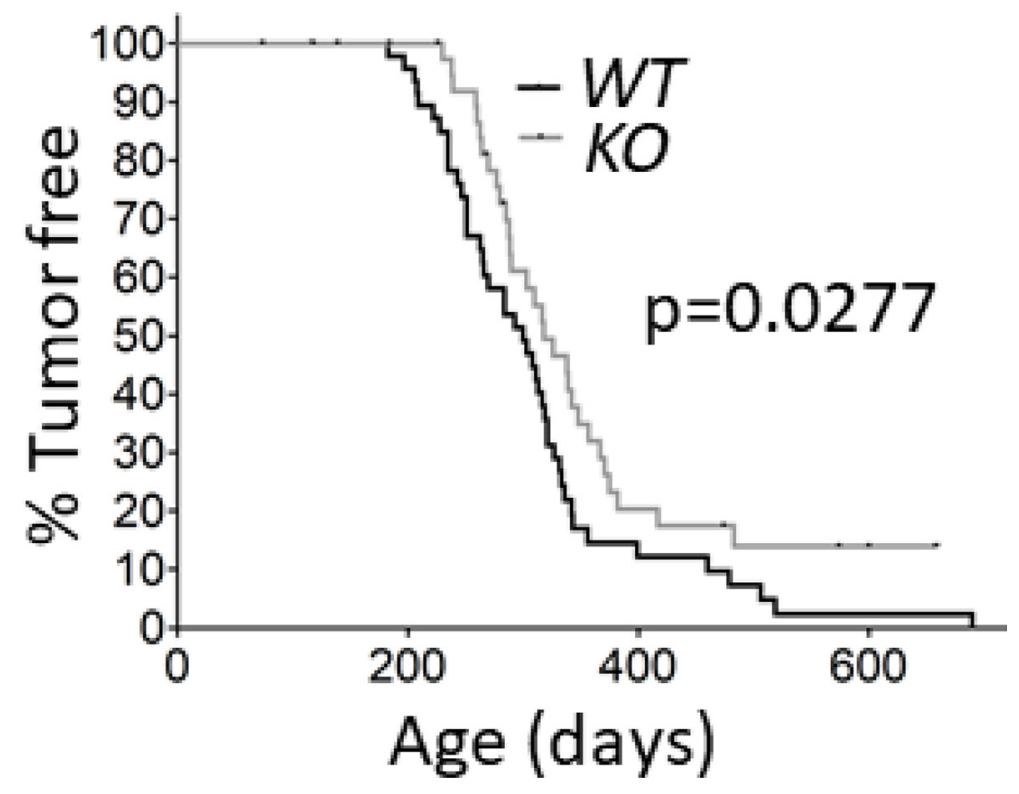

Figure 1: Deletion of capns1 in the mammary epithelium delays Her2/Neu-driven tumorigenesis. $N I C$ capns $1^{\text {flox/flox }}(K O)$ or NIC capns $1^{+/+}(W T)$ female mice were assessed for tumor onset by weekly palpitation. Median tumor onset was 318 vs 300 days, $(n=43$ vs 48 , respectively, $p=0.0277^{*}$ Gehan-Breslow-Wilcoxon Test).
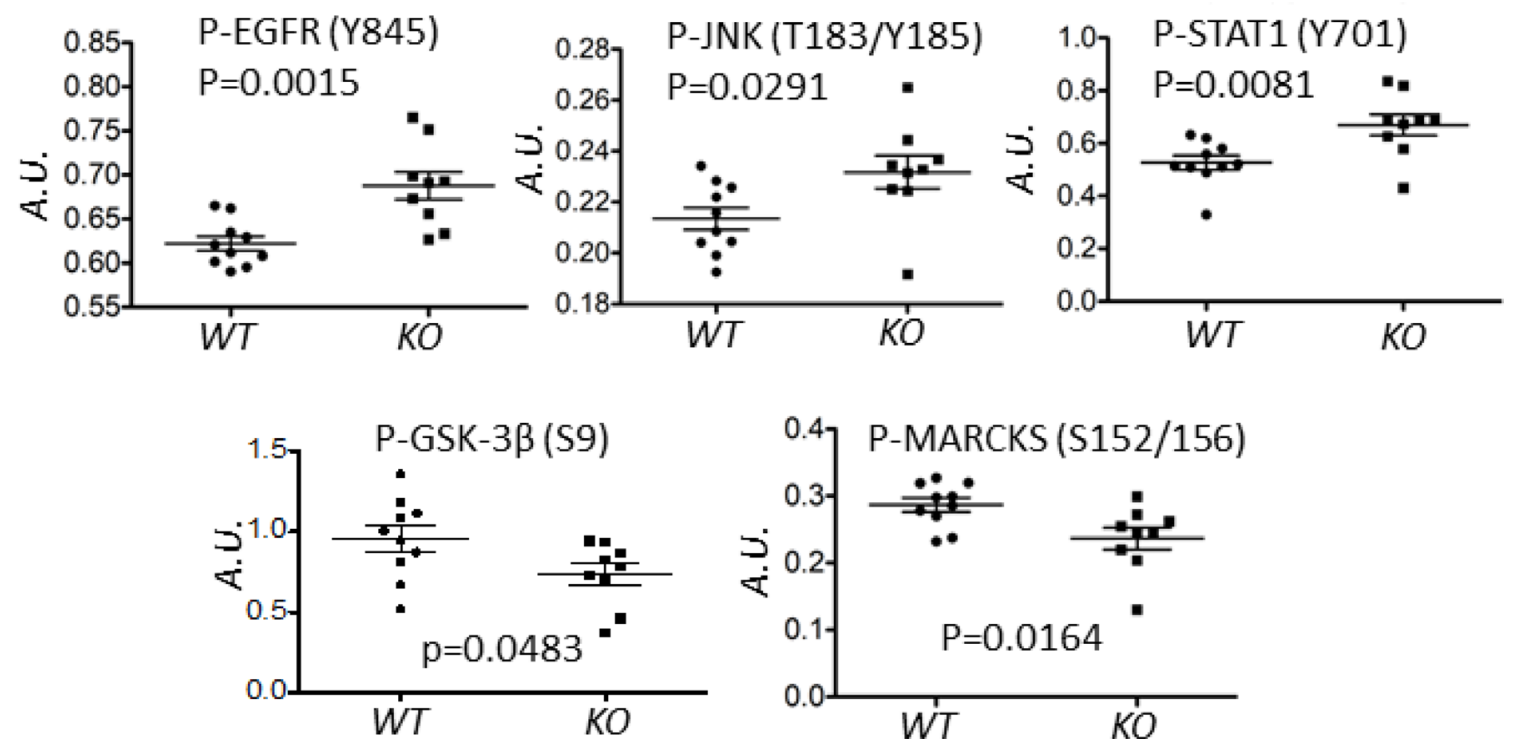

Figure 2: Deletion of capns1 in Her2/Neu-driven mouse mammary tumors correlates with a differential phosphoproteome. Spontaneous tumors arising in NIC capns $1^{\text {flox/flox }}(K O, n=9)$ or $N I C$ capns $1^{+++}(W T, n=10)$ female mice were subject to RPPA analysis with 128 antibodies. The indicated phosphoproteins displayed significantly different signal intensities (A.U.). 


\section{Capns1 KO sensitizes MTECs to doxorubicin and lapatinib challenge}

Lapatinib is a small molecule tyrosine kinase inhibitor of both HER2 and EGFR. It has similar clinical efficacy to trastuzumab in a neoadjuvant setting [33], and may also be used as a second-line therapy when resistance to trastuzumab develops [34, 35]. Doxorubicin is an anthracycline which causes DNA damage by targeting topoisomerase II and is widely used as a cancer therapeutic. Doxorubicin resistance is mediated in part by members of the $\mathrm{ABC}$ family of transporters including P-glycoprotein (Pgp) and multidrug resistance protein 2 (MRP2). We recently reported that expression of Pgp and MRP2, and sensitivity to doxorubicin correlate with calpain-1/2 expression [25]. Furthermore, cleavage of topoisomerase II $\alpha$ by calpain- 2 has been suggested as an additional mechanism of doxorubicin resistance [36]. Thus, we sought to determine whether loss of calpain- $1 / 2$ in a HER2 ${ }^{+}$tumor cell line model might cooperate with therapeutic challenge from these two commonly used treatments of breast cancer. Lapatinib exposure for $72 \mathrm{~h}$ across a range of doses was associated with a trend towards reduced viability in capns 1 KO MTECs, with significantly reduced viability at both $15 \mu \mathrm{M}$ and $17 \mu \mathrm{M}$ ( $p=0.0033$ and $p=0.0066$, respectively) (Figure 5A). Upon challenging capns1 KO or WT MTECs with doxorubicin for $72 \mathrm{~h}$, a similar trend towards increased cytotoxicity in KO MTECs was observed, with significantly reduced viability noted at $1000 \mathrm{nM}(p=0.0271)$ (Figure 5B).

\section{Deletion of capns1 blocks MTEC tumorigenesis in an orthotopic engraftment model}

Previously, we showed that shRNA-mediated knockdown of capn 2 in murine mammary carcinoma engraftment model [9] or knockdown of capns 1 in a human triple negative breast cancer xenograft model [25] attenuated tumor growth at the orthotopic site. Here, using the floxed capns 1 HER2/NEU-driven MTEC carcinoma model, we asked if complete ablation of calpain-1 and calpain-2 would result in a more effective block in tumorigenesis in an orthotopic engraftment model. WT MTECs produced rapidly growing tumors with a mean onset time of 29 days, while tumor onset was delayed to a mean of 79 days after engraftment with KO MTEC cells, at which point $\mathrm{KO}$ tumors grew at comparable rates to WT tumors (Figure 6A). When resected and assessed by immunoblotting, comparable levels of CAPNS1 were observed in both WT and KO tumors (Figure 6B). Since engrafted KO cells showed no detectable CAPNS1 in immunoblotting (Figure 3), this indicates that $\mathrm{KO}$ tumors arose from rare "escaper" WT MTECs which had not undergone CRE-mediated deletion of the floxed capns 1 alleles and required several more weeks to emerge as palpable tumors. Delayed tumor growth behavior was validated in an independent experiment with essentially identical results (Supplementary Figure 2).

Tumor progression can be limited by failure to drive de novo angiogenesis in response to hypoxia due to an inability to trigger an angiogenic switch [37]. Given that engrafted capsn1 KO MTECs failed to develop palpable
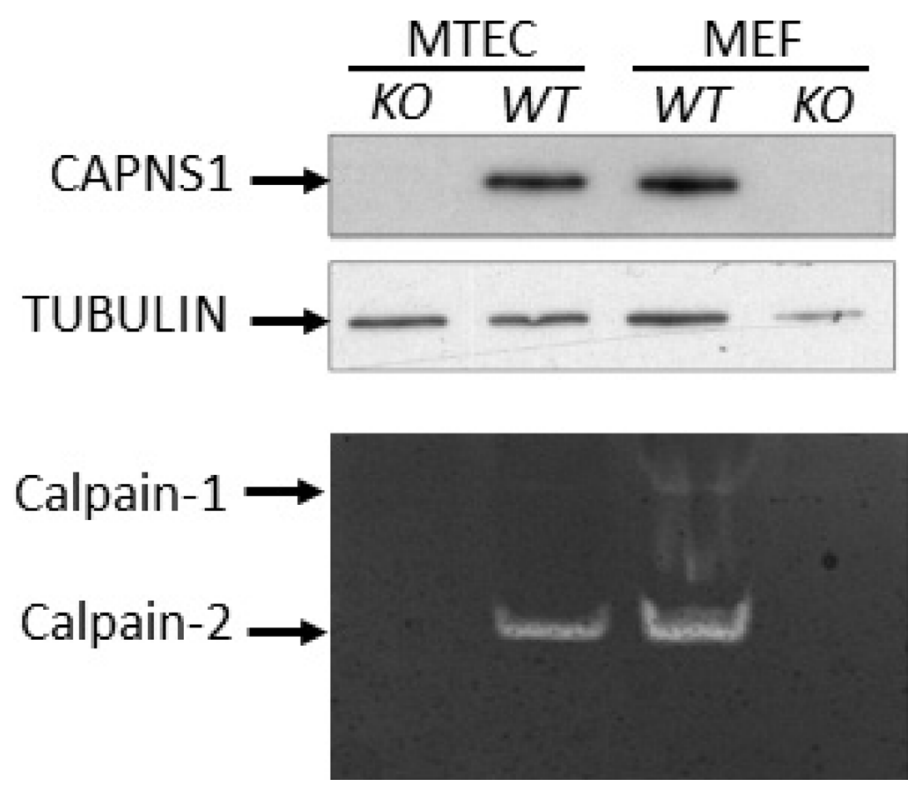

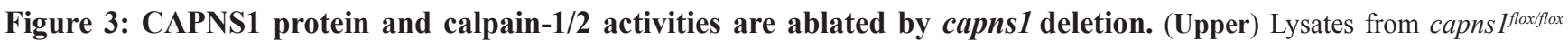
MTECs transduced with Cre-expressing $(K O)$ or control $(W T)$ retroviruses; or capns $1^{+/+}(W T)$ or capns $1^{-/-}(K O)$ mouse embryonic fibroblasts (MEFs) were subjected to immunoblotting analysis with antibodies recognizing CAPNS1 or tubulin. (Lower) Casein zymography assessment of calpain-1 and calpain-2 activities in lysates from the same panels of MTEC and MEF cells. 

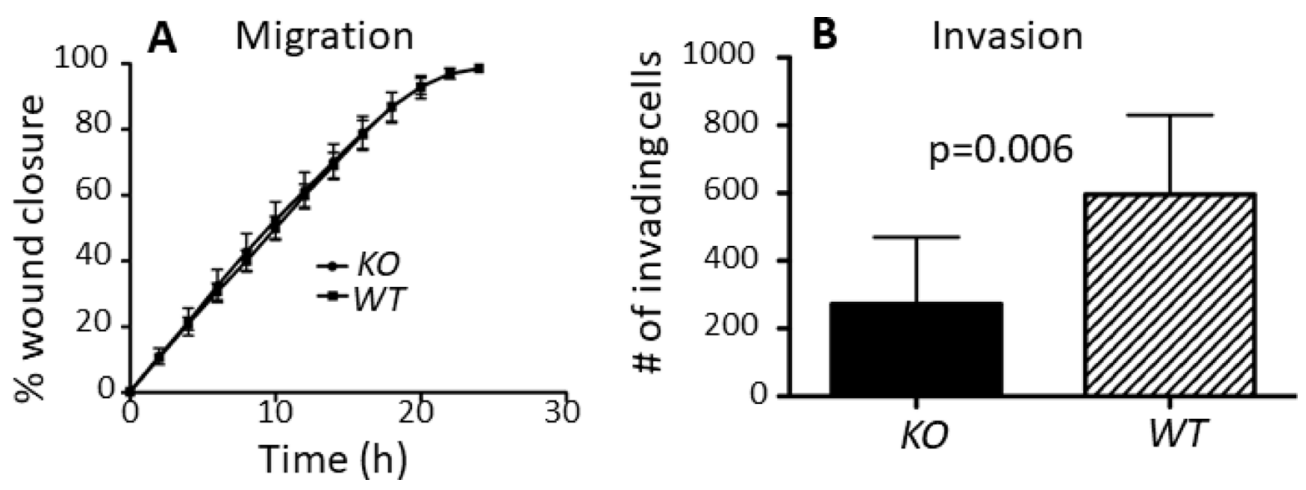

Figure 4: capns1 KO is associated with attenuated MTEC in vitro invasion but no effect on migration. (A) Temporal profiles of capns $1 K O$ and WT MTEC migration behavior in scratch-wound healing assays. Fifteen thousand MTECs were seeded on ImageLock 96-well plates and confluent monolayers were scratch-wounded after an overnight incubation. Migration was monitored in an IncuCyte system for $24 \mathrm{~h}$. Data are the means \pm SD of three independent experiments run in sextuplicate. (B) Boyden chamber assays measured capns $1 K O$ and WT MTEC invasion after $24 \mathrm{~h}$ through $8 \mu \mathrm{m}$ pores of transwells coated with $15 \mu \mathrm{g}$ of matrigel. Data are means $\pm \mathrm{SD}$ of two independent experiments run in triplicate $(p=0.006$, student's $t$-test).
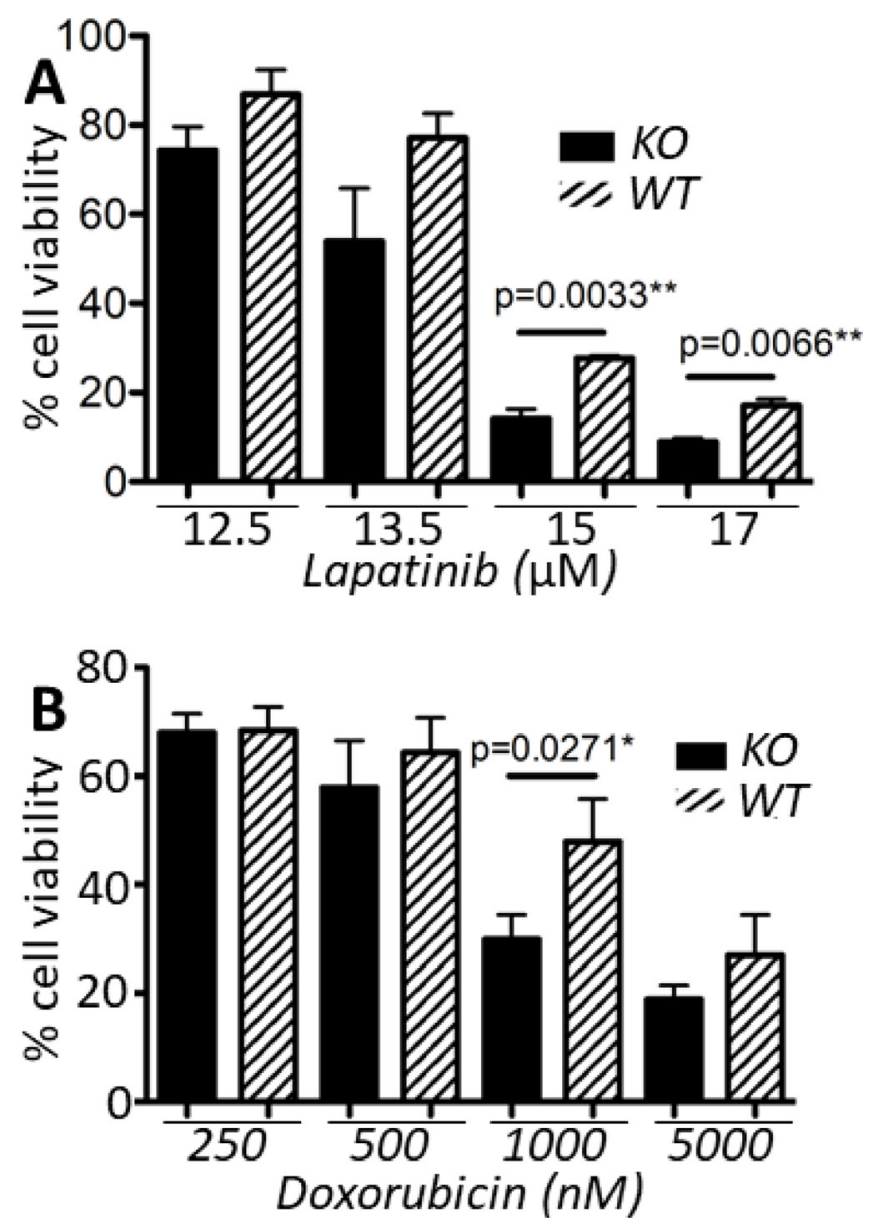

Figure 5: capns1 KO correlates with enhanced sensitivity to lapatinib and doxorubicin. Two $\times 10^{4}$ capns $1 \mathrm{KO}$ or $W T$ MTECs were seeded on 96 well plates, then cultured overnight. The following day, cells were treated for $72 \mathrm{~h}$ with (A) lapatinib or (B) doxorubicin at the indicated concentrations. Cell viability was assessed at endpoint using the PrestoBlue viability reagent. Data are means $\pm \mathrm{SD}$ of three independent experiments with experimental triplicates ( $p$, student's $t$-test). 
tumors, we next explored the possibility that calpain-1/2 deficient cells might not be able to respond in vivo to hypoxia during tumor growth. Hypoxia-inducible factor 1 alpha (HIF $1 \alpha)$ is a transcription factor that is normally degraded by the proteasome via hydroxylation by prolyl hydroxylases under normoxic conditions, but is stabilized under hypoxic conditions to direct transcription of genes containing pro-survival hypoxic response elements including VEGF, which is needed to promote tumorassociated neoangiogenesis [38]. Calpain has been shown to modulate a hypoxic response through generation of a filamin-A fragment which mediates nuclear localization of HIF1 $\alpha$ [39]. To test the involvement of calpain in HIF $1 \alpha$ regulation in MTECs, we compared HIF $1 \alpha$ levels in whole cell lysates and nuclear extracts from capns 1 $\mathrm{KO}$ and WT cells cultured at either hypoxic $(0.1 \%)$ or ambient $(20 \%)$ oxygen concentrations for 24 hours in the absence of serum. Cobalt chloride was used as a positive control for HIF $1 \alpha$ stabilization. Hypoxia or $\mathrm{CoCl}_{2}$ stabilized comparable levels of HIF $1 \alpha$ in WT and KO MTECs in both whole cell lysates and nuclear fractions (Supplementary Figure 3), suggesting that calpain does not play a key role in the angiogenic switch in this model system.
The production and activation of matrix metalloproteases (MMPs) has also been linked to tumor growth, invasion and metastasis [40-42]. Gelatin zymography analysis of conditioned media from capns 1 KO and WT MTECs revealed abundant levels of MMP2 and lower levels of MMP9, but there were no differences between the WT and KO MTECs (Supplementary Figure 4).

\section{capns1 KO in MTECs correlates with enhanced EGFR expression and sustained EGF response}

EGFR is a key dimerization partner of HER2, and is frequently expressed in breast carcinomas [43]. Deletion of capns 1 was associated with enhanced phosphorylation of EGFR (Y845) in tumors from the NIC model (Figure 2); we therefore tested EGF-induced activation of EGFR in vitro in the MTEC system. Overnight serum starvation followed by EGF stimulation resulted in a rapid induction in pY845-EGFR levels in both capns1 KO and WT MTECs (Figure 7A), however there was a difference in kinetic behavior, with more sustained EGFR activation in the capns 1 KO MTECs; which correlated with more robust and sustained activation of MEK and ERK, as shown by their phosphorylation at activation loop
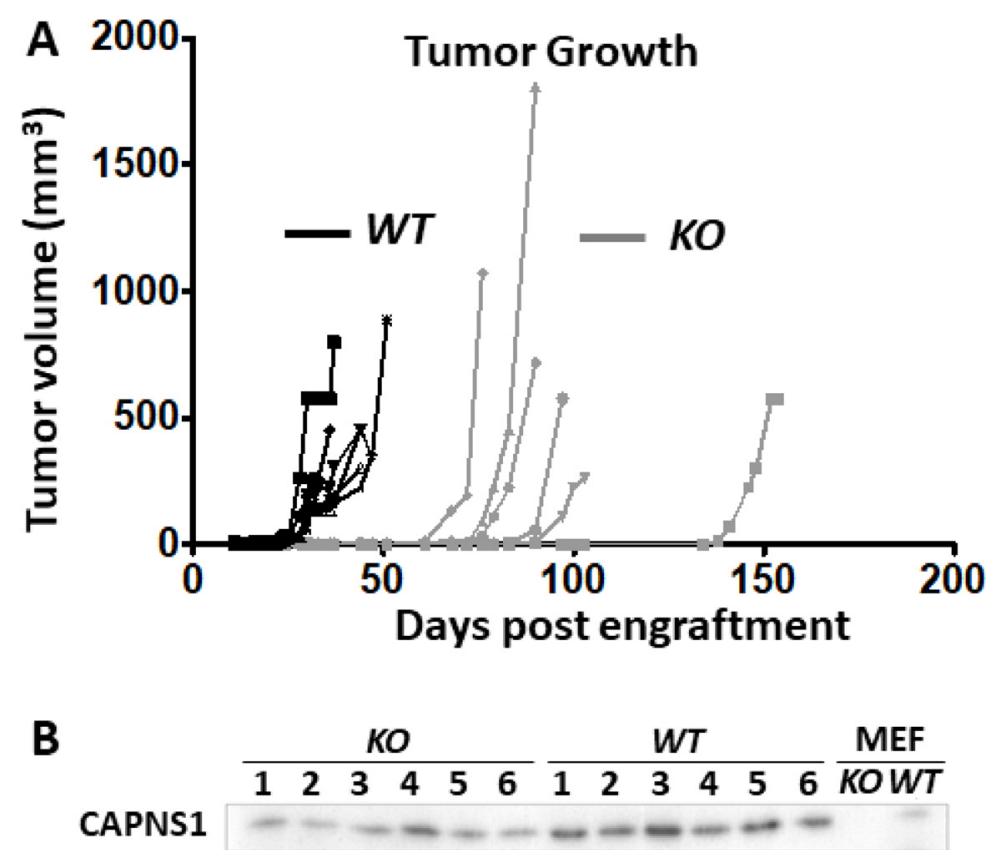

TUBULIN

Figure 6: capns1 KO is associated with reduced MTEC tumorigenic potential. One $\times 10^{6}$ capns1 KO or WT MTECs were engrafted into the number four mammary glands of female $\operatorname{Rag}^{-/} I L-2 \operatorname{Rgc}^{-/}$mice ( $n=6$ for each cohort). (A) Caliper measurements of tumor volumes. Median time to onset of palpable tumors at the engraftment site were 79 or 29 days for $K O$ and $W T$, respectively $\left(p=0.0009^{* * *}\right.$, Log-rank (Mantel-Cox) test). (B) Late arising tumors in mice engrafted with capns1 KO MTECs display CAPNS1 expression. Immunoblot analysis of tumor lysates reveals CAPNS1 expression in tumors from both capns $1 \mathrm{WT}$ and $\mathrm{KO}$ engrafted MTECs. Lysates from $W T$ and $K O \mathrm{MEF}$ cells served as positive and negative controls for CAPNS1. Immunoblotting for tubulin confirmed comparable sample loading. 
sites (Figure 7A, 7C, 7D). We also noted an increase in steady-state levels of EGFR in the capns 1 KO MTECs (Figure 7B). These data are consistent with a role for calpains-1/2 in EGFR signaling to the RAS-MAPK pathway.

\section{DISCUSSION}

Approximately 15-20\% of newly diagnosed breast cancers are the highly aggressive HER2 ${ }^{+}$subtype [44], and despite treatment with chemotherapy and targeted therapeutics such as trastuzumab and lapatinib, half of these patients relapse with resistant disease within one year [45]. These clinical findings underscore the urgent need to develop more effective treatments for $\mathrm{HER}_{2}{ }^{+}$breast cancer.
This will require a better understanding of the biology of these tumors, including the signaling pathways that confer resistance to current treatments and identification of druggable components of these pathways that might represent novel combinatorial therapeutic targets.

Our previous work has shown that the ubiquitously expressed calpain- 1 and -2 isoforms regulate cell survival in response to cytotoxic challenges $[10,11]$ and promote breast cancer cell line resistance to chemotherapeutics including doxorubicin and cisplatin [25]. We also showed that capn 2 knockdown in a mouse mammary carcinoma cell line was associated with reduced tumor growth in a mouse orthotopic engraftment model [9], and capns 1 knockdown in the MDA-MB-231 triple negative breast cancer cell line correlated with reduced tumor growth and
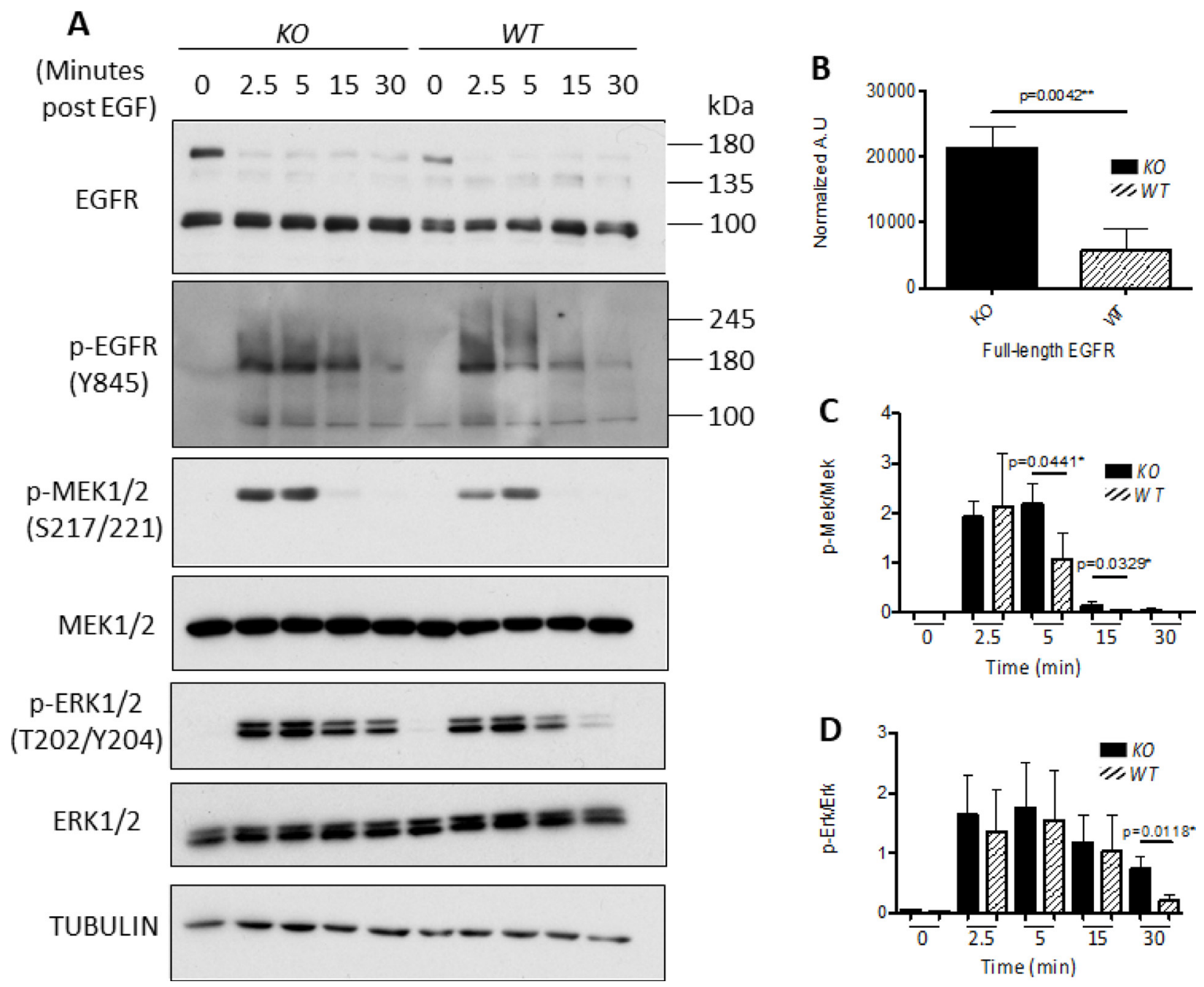

Figure 7: Knockout of calpain correlates with enhanced EGFR expression and sustained MAPK signaling. $7.5 \times 10^{4} \mathrm{WT}$ or capns1 KO MTECs were seeded overnight in $60 \mathrm{~mm}$ dishes. The following day cells were washed with PBS and changed to serum-free media. MTECs were stimulated with $50 \mathrm{ng} / \mathrm{mL}$ of EGF for the indicated times, lysed in RIPA buffer and assessed by immunoblotting. (A) capns1 KO correlates with activation of the MAPK pathway in response to EGF. (B) Full length EGFR levels are elevated in capns 1 KO MTECs after overnight serum starvation. (C) capns $1 \mathrm{KO}$ is associated with greater EGF-induced MEK1/2 phosphorylation. (D) capns1 KO is associated with greater EGF-induced ERK1/2 phosphorylation. 
metastasis in a mouse orthotopic xenograft model, and this effect was enhanced by combination with the HSP90 inhibitor, 17-AAG [25].

The relationship between expression of calpains and clinical outcomes in various cancers are being explored $[8$, 46]. Of specific relevance to this study, CAPN1 expression in HER $2^{+}$breast cancer has been positively correlated with shorter relapse-free survival and resistance to trastuzumab [22]. This is consistent with in vitro studies showing that capns 1 expression was associated with reduced trastuzumab sensitivity in the HER2 $2^{+}$human breast cancer cell lines SKBR3 and BT474 [47].

Here we report the first study exploring the involvement of ubiquitously expressed classical calpain-1/2 isoforms in a genetically engineered mouse model of spontaneous tumorigenesis driven by the HER2/NEU oncogene. By deleting capns 1 in the mammary epithelium, we show that calpains-1/2 are not required for HER2/ NEU tumorigenesis, but their absence is associated with a significant delay in tumor onset (Figure 1). Phosphoproteomic analysis of these tumors was performed to explore the possibility that differences in the carcinogenic process in the presence or absence of calpains- $1 / 2$ might be revealed by distinct activation states of specific signaling nodes. This analysis detected significant differences in 5 phosphoproteins (EGFR, GSK-3 $\beta$, JNK, MARCKS and STAT-1) out of the 128 proteins queried (Figure 2), suggesting that the carcinogenic program pursued by these HER2/NEU-driven tumors was subtly different in the absence of calpains- $1 / 2$.

Glycogen synthesis kinase $3 \beta$ (GSK-3 $\beta$ ) has complex roles in cell signaling, including a tumor suppressor function through inhibition of the $\beta$-catenin complex [48]. GSK-3 $\beta$ is inhibited by AKT-mediated S9 phosphorylation and activated by PP2A-mediated dephosphorylation. Reduced p-S9-GSK-3 $\beta$ levels in capns $1 \mathrm{KO}$ tumors is consistent with previous observations of reduced AKT activation in capns1 KO MEF cells [11], and increased PP2A levels in capn2 knockdown mammary carcinoma cells [9] and capns1 KO MEFs [49]. Thus, a GSK-3 $\beta$ tumor suppressor role could contribute to delayed tumor onset in the NIC capns1 KO mice.

The c-Jun N-terminal kinase (JNK) is activated in response to a number of ligands and stress stimuli and subsequently regulates transcription, migration and apoptosis [50]. Increased pT193/Y185-JNK in capns1 $\mathrm{KO}$ tumors was surprising since capns1 KO MEF cells had been shown to display reduced activation in response to endoplasmic reticulum stress [10]. This difference may reflect distinct effects of calpain deficiency in cancer cells and immortalized fibroblasts, or distinct context-specific roles of calpain in endoplasmic reticulum stress and tumorigenesis.

Calpain-mediated cleavage of protein kinase $\mathrm{C}$ (PKC) is an evolutionally conserved mechanism for PKC activation [51], and PKC $\beta$ deletion was correlated with suppressed tumorigenesis in a transgenic mouse model of breast cancer [52]. Myristoylated alanine-rich protein kinase $\mathrm{C}$ substrate (MARCKS) displayed reduced pSer152/S162 levels in capns1 KO tumors, consistent with a role for calpain in PKC activation in these tumors. Elevated p-Ser-152/156-MARCKS levels have been positively associated with more aggressive breast cancer and reduced sensitivity to chemotherapy in breast cancer cell lines [53]. These observations suggest that reduced calpain-mediated activation of PKC may have also contributed to delayed tumor onset in the NIC capns $1 \mathrm{KO}$ mice.

STAT-1 behaves as a tumor suppressor through promotion of apoptosis as well as inhibition of angiogenesis, tumor growth, and metastasis [54]. A role for STAT-1 in suppression of epithelial to mesenchymal transition has also been described [55]. Increased pY701STAT-1 observed in NIC capns1 KO tumors could therefore reflect a role for calpain in regulating these tumor suppressor functions.

EGFR represents an important target since it is often dysregulated in human cancers. EGFR forms heterodimers with HER2 and contributes to survival and proliferative signaling in response to EGF [56]. Enhanced phosphorylation of the EGFR activation loop Y845 residue in capns $1 \mathrm{KO}$ tumors indicated a higher level of activated EGFR (Figure 2). Both EGFR [57] and HER2 [19] have been identified as substrates of calpain, therefore this observation may simply be a reflection of an accumulation of more mature EGFR in the absence of calpain. Given the importance of this signaling node in HER2 tumorigenesis, we focused further study on it using the capns 1 floxed MTEC model system. There was significantly more of the presumptive mature $\sim 150 \mathrm{kDa}$ EGFR species in capns $1 \mathrm{KO}$ MTEC cells (Figure 7A, 7B), which supports a role for calpain-1/2 in regulating EGFR levels. While this presumptive mature EGFR is rapidly downregulated after EGF treatment in both capns $1 \mathrm{KO}$ and WT MTECs, more of this $150 \mathrm{kDa}$ band persists in $\mathrm{KO}$ cells, and more of a faster migrating $135 \mathrm{kDa}$ band was observed in the WT cells. It was tempting to predict that this smaller species arose by calpain cleavage of EGFR, since both EGFR [57] and HER2 [19] have been identified as a substrates of calpain. However, it is more likely that this $135 \mathrm{kDa}$ band corresponds to immature EGFR in the ER/Golgi compartment. A prominent band at $\sim 100 \mathrm{kDa}$ was detected with antibodies to both EGFR and pY845EGFR (Figure 7A). HER2 has been reported to give rise to a $95 \mathrm{kDa}$ species which is associated with elevated $\mathrm{PI} 3 \mathrm{~K} / \mathrm{AKT}$ signaling and trastuzumab resistance [58-60], and calpain is implicated the generation of intracellular fragments of HER2, as well as the activation of AKT $[11,19,47]$. EGFR is also a known calpain substrate, but the occurrence of this $\sim 100 \mathrm{kDa}$ species in the MTEC system was not correlated with capns 1 status, so it cannot be a uniquely calpain-generated fragment of EGFR. HER2 
levels were very low in these MTEC cells, and even after forced ectopic over-expression of HER2, we were unable to correlate the presence of unique HER2 fragments with capns 1 status (unpublished observation).

Interestingly, EGF-induced pY845-EGFR levels persisted for longer in capns1 KO MTECs (Figure 7A), and this correlated with persistence of activated MEK1/2 and ERK1/2 levels (Figure 7A, 7C, 7D). These observations are somewhat surprising given the delayed tumor onset in the capns $1 \mathrm{KO}$ NIC transgenic model (Figure 1) and the complete block in tumorigenic potential in the capns $1 \mathrm{KO}$ MTEC engraftment model (Figure 6 and Supplementary Figure 2). However, delayed tumor onset correlating with increased signaling through the ERK1/2 pathway has been observed previously in the $\mathrm{neu}^{\mathrm{NT}}$ transgenic mice model and MTEC lines derived from them [61]. Similar observations have been described by others as biphasic behavior of ERK signaling, capable of promoting differentiation or quiescence with high ERK activation vs mitogenesis with lower ERK activation [62-64]. We speculate that this may be a reflection of compensatory signaling in the absence of calpain.

We also show that capns $1 \mathrm{KO}$ in MTECs is associated with increased sensitivity to both doxorubicin and lapatinib (Figure 5). Capns1 KO tumors arising in vivo in the NIC mice displayed enhanced activation of EGFR (Figure 2), and this was phenocopied in vitro in the MTEC model using EGF stimulation (Figure 7). Enhanced activation of EGFR may reflect a survival response to the absence of calpain. Since lapatinib inhibits both HER2 and EGFR, enhanced lapatinib sensitivity of capns 1 KO MTECs might be attributed to an attenuation of compensatory EGFR signaling when calpain is ablated. In the case of doxorubicin, resistance is mediated in part by expression of Pgp, and we have shown that calpain expression correlates with Pgp expression in MEFs [25]. Furthermore, calpain cleavage of topoisomerase II $\alpha$ has been shown to promote doxorubicin resistance [36]. In summary, survival responses triggered by challenge with doxorubicin and lapatinib may engage calpain-dependent pathways, which bodes well for the potential of calpain inhibition to enhance the efficacy of these therapeutics.

The most compelling observation in this study was the loss of the tumorigenic potential of MTECs upon capns $1 \mathrm{KO}$. While we cannot rule out the possibility that capns $1 \mathrm{KO}$ tumors might have emerged if we had waited longer than 150 days, that was not observed in any of the several dozen late arising tumors from engrafted capns 1 $K O$ MTECs. Angiogenesis is known to be required for the growth of tumors beyond a size of approximately $2 \mathrm{~mm}^{3}$. As calpain cleavage of filamin-A has been implicated in the nuclear localization of HIF1 $\alpha$ [39], we initially speculated that failure to trigger the angiogenic switch might account for these results. However, overall production as well as nuclear localization of HIF $1 \alpha$ were unaffected by calpain status in vitro (Supplementary
Figure 3). MMP-2 and MMP-9 production in vitro were also unaffected (Supplementary Figure 4). This suggests that the block in tumorigenesis at the orthotopic site might relate to a role for calpain in stromal conditioning. For example, loss of calpain may impact the ability of engrafted MTECs to recruit and promote pro-tumorigenic behavior in cancer-associated fibroblasts $[65,66]$.

capns $1 \mathrm{KO}$ in this MTEC model did not reduce cell migration in a scrape-wound assay (Figure 4A); however, capns $1 \mathrm{KO}$ was associated with attenuated invasive behavior in matrigel-coated Boyden chamber assays (Figure 4B). This is interesting since capns $1 \mathrm{KO}$ in MEFs has previously been associated with defects in cell migration [15] as well as invasion [17]; and capns 1 knockdown in MDA-MB-231 cells correlated with reduced migration and invasion [25]. Calpain has also been linked with lamellipodia dynamics at the leading edge and focal adhesion turnover at the trailing edge of fibroblasts $[16,18]$. We were surprised that loss of calpain-1/2 in the MTEC system did not attenuate their migration behavior, yet defective invasive behavior was conserved. MMPs are important players in cell invasion, and we have previously linked calpain to MMP production [17]. EGFR and PI3K-AKT signaling has been implicated in the production of MMPs [67] and although we were unable to identify differential levels of active MMP-2 and MMP-9 by gelatin zymography (Supplementary Figure 4), this assay is limited, as it dissociates tissue inhibitors of metalloproteineases (TIMPs), thus we cannot exclude the possibility that calpain participates elsewhere in the MMP activation cascade [68].

In conclusion, our in vivo results demonstrate that loss of calpain-1/2 delays spontaneous tumor onset in a model of HER2 ${ }^{+}$tumorigenesis but does not prevent progression. The possibility that other CAPNS1independent calpain isoforms could provide redundant functions to potentiate the delayed tumor onset has not been addressed in this study. Phosphoproteomic analysis suggests that tumors arising in the presence of calpain- $1 / 2$ engage in subtly different pro-tumorigenic signaling than tumors arising in the absence of calpain-1/2. Differences in the phosphorylation states of EGFR, GSK-3 $\beta$, JNK, MARCKS and STAT-1 in capns 1 KO tumors represent important leads for future studies aimed at elucidating the molecular involvement of calpain in HER2 $2^{+}$breast cancers. Most significantly, calpain was critically required for tumorigenesis in an orthotopic engraftment model, suggesting its inhibition might be an effective treatment strategy. Finally, we show that KO of capns 1 enhances cytotoxicity mediated by doxorubicin and lapatinib. Taken together, these results suggest that inhibition of calpain in established malignancies may confer therapeutic benefits and may also enhance the efficacy of currently employed therapeutics like doxorubicin and lapatinib. This underscores the need to develop clinically effective pharmacological inhibitors of calpain-1/2. 


\section{MATERIALS AND METHODS}

\section{Spontaneous tumor development and reverse- phase protein array analysis}

Transgenic mice expressing oncogenic rat HER2/ NEU and CRE-recombinase in mammary epithelial cells from a bicistronic transcript under the control of the mouse mammary tumor virus promoter (MMTV-NEU-IRES-CRE/ otherwise known as NIC) [28] were crossed with capns 1 floxed mice [6] to produce compound NIC capns $1^{\text {flox } f l o x}$ or NIC capns $1^{+/+}$females. Mammary glands were palpated weekly by an individual who was blinded to mouse genotypes to determine the age when spontaneous tumor formation occurred. At endpoints, mice were euthanized, tumors resected, snap frozen in liquid $\mathrm{N}_{2}$ and prepared for reverse-phase protein array (RPPA) analysis using recipe 10 and a panel of 128 antibodies as described $[29,30]$.

\section{Cell line derivation}

Mammary tumor epithelial cells (MTECs) were derived from $n e u^{N T}$ transgenic mice (strain TG.NK obtained from Jackson Labs) expressing oncogenic rat HER2/ NEU in mammary epithelial cells under the control of the mouse mammary tumor virus promoter [31] crossed with capns $1^{\text {floxflox }}$ mice [6]. A tumor from a $n e u^{N T}$ capns $1^{\text {flox } f l o x}$ female mouse was excised and a cell suspension was developed by mechanical disruption and digestion with $0.25 \%$ trypsin, followed by culture in improved minimum essential medium (IMEM, Corning) supplemented with $1 \%$ fetal bovine serum (FBS; Sigma), $10 \mu \mathrm{g} / \mathrm{mL}$ insulin (Sigma), $15 \mathrm{ng} / \mathrm{mL}$ EGF (Sigma), $1 \mu \mathrm{g} / \mathrm{mL}$ hydrocortisone (Sigma), and $20 \mathrm{nM}$ estrogen (Sigma) as described [61,69] until an immortalized cell line was achieved. The FBS concentration for immortalized cells was increased to $5 \%$ and supplemented with insulin, EGF and hydrocortisone. Estrogen was discontinued after 10 passages, and immortalized cells were subsequently cultured in IMEM, supplemented with 5\% FBS, and 1\% antibiotic-antimycotic (AA; Gibco) ("complete IMEM"). MTECs were maintained in a humidified incubator at $37.5^{\circ} \mathrm{C}, 5 \% \mathrm{CO}_{2}$.

To produce capns1 knockout (KO) and vector control (WT) MTECs, $2.5 \times 10^{5}$ cells were seeded on a $60 \mathrm{~mm}$ dish (Sarstedt) and transduced with retrovirus expressing CRE recombinase or an empty vector [6] in a pMSCV-puro vector (Clontech). Puromycin (Gibco) was used as a selectable marker, and disruption of the floxed capns 1 gene was validated by CAPNS1 immunoblotting and HEPES-imidazole casein zymography. Cells surviving culture in $2 \mu \mathrm{g} / \mathrm{mL}$ puromycin were lysed into radioimmunoprecipitation assay buffer for immunoblotting (RIPA; $50 \mathrm{mM}$ Tris- $\mathrm{HCl}, 150 \mathrm{mM} \mathrm{NaCl}, 1 \% \mathrm{NP}-40$, $0.1 \%$ SDS and $0.5 \%$ sodium deoxycholate supplemented with protease and phosphatase inhibitors $1 \mathrm{mM}$ sodium orthovanadate (Sigma), $1 \mathrm{mM}$ phenylmethane sulfonyl fluoride, $5 \mu \mathrm{g} / \mathrm{mL}$ leupeptin (Sigma), and $2 \mu \mathrm{g} / \mathrm{mL}$ aprotinin (Sigma)); or lysed into HEPES/ Triton X-100 lysis buffer for HEPES-imidazole casein zymography as described [70]. Lysates were clarified by centrifugation $\left(12,000 \times \mathrm{g}\right.$ for 15 minutes at $\left.4^{\circ} \mathrm{C}\right)$, and protein quantification was performed using the Pierce bicinchoninic acid (BCA) kit (Thermo Scientific). Capns 1 $\mathrm{KO}$ was validated by immunoblotting using an in-house rabbit polyclonal antibody generated against bacterially expressed rat calpain-2, which detects murine CAPN2 and CAPNS1 polypeptides [71], and by casein zymography to assess calpain-1 and calpain-2 enzymatic activity. Lysates from capns $1 \mathrm{KO}$ or WT mouse embryonic fibroblasts (MEFs) [6] were used as controls for immunoblotting and zymography.

\section{Migration, invasion, chemosensitivity, hypoxic response, and EGF signaling analysis}

To assess migration, $1.5 \times 10^{4} \mathrm{WT}$ or capns 1 KO MTECs were seeded in sextuplicate on 96-well ImageLock plates (Essen Bioscience) and allowed to adhere overnight. The following day cell monolayers were scrape-wounded using the IncuCyte Wound Maker (Essen Bioscience) and washed twice with media. Cells were then cultured in $100 \mathrm{~mL}$ of complete IMEM and placed in an IncuCyte system (Essen Bioscience) maintained at $37^{\circ} \mathrm{C}$, $5 \% \mathrm{CO}_{2}$ and imaged with a $10 \times$ objective every $2 \mathrm{~h}$ until the wounds had closed.

For cell invasion assays, $8 \mu \mathrm{m}$-pore transwells (Corning \#353097) were coated with $15 \mu \mathrm{g}$ of growthfactor reduced matrigel (VWR) in $25 \mu \mathrm{L}$ of serum-free IMEM and allowed to dry overnight. The following day, the matrigel was rehydrated with serum-free IMEM for $2 \mathrm{~h}$ in a humidified incubator at $37^{\circ} \mathrm{C}, 5 \% \mathrm{CO}_{2}$. One $\times 10^{5}$ WT or capns $1 \mathrm{KO}$ cells were added in triplicate wells to the top chambers in serum-free IMEM. Media in the lower chambers was replaced with complete IMEM. Cells were allowed to invade for $24 \mathrm{~h}$, then non-invading cells were removed from the top chambers with cotton swabs, and invading cells in the lower chambers were fixed in icecold methanol and stained with DAPI (Sigma) and imaged under a $10 \times$ objective.

To assess cytotoxicity, $2 \times 10^{4} \mathrm{WT}$ or capns $1 \mathrm{KO}$ MTECs were seeded in 96-well plates (Grenier Bio-One) in triplicate and allowed to adhere overnight. Increasing concentrations of doxorubicin (Sigma) or lapatinib (Toronto Research Chemicals) were added to the wells and cells cultured for $72 \mathrm{~h}$. At endpoint, the PrestoBlue reagent (ThermoFisher) was utilized to quantify cell viability by measuring fluorescence on a SpectraMax M2 plate reader $(590 \mathrm{~nm})$. Chemosensitivity experiments were analyzed using Prism Graphpad.

Hypoxic response was assessed by seeding $1.5 \times 10^{6}$ WT or capns 1 KO MTECs in $10 \mathrm{~cm}$ dishes (Sarstedt) and 
allowing cells to adhere overnight in complete IMEM. The following morning cells were washed once with PBS and changed to serum-free IMEM. Positive controls were treated with $100 \mu \mathrm{M}$ of cobalt chloride and half of the dishes were transferred to a hypoxic incubator $\left(0.1 \% \mathrm{O}_{2}\right)$. After 24 hours cells were placed on ice, rinsed once with PBS and lysed into RIPA (as described previously) or nuclear extraction buffer (20 mM HEPES) pH 7.4, $10 \mathrm{mM} \mathrm{KCl,} 2 \mathrm{mM} \mathrm{MgCl}_{2}$, 1 mM EDTA, 1 mM EGTA, 1 mM DTT supplemented with protease and phosphatase inhibitors as previously described. For nuclear extracts, cells were collected with a cell scraper and passed through a 27-gauge needle 10 times. Lysates were then incubated on ice for 20 minutes and centrifuged $720 \times \mathrm{g}$ for 5 minutes at $4^{\circ} \mathrm{C}$. The pellet was then washed once in $500 \mu \mathrm{L}$ of nuclear extraction buffer and passed through a 25-gauge needle 10 times, followed by centrifugation for 10 minutes at $720 \times \mathrm{g}$. The supernatant was discarded, and the pellet was resuspended in $2 \times$ SDS sample buffer (100 mM Tris- $\mathrm{HCl}$ pH 6.8, 0.2\% bromophenol blue, 20\% glycerol, $200 \mathrm{mM}$ DTT) and boiled for 5 minutes. Protein quantification was performed using the DC Protein Assay (BioRad) according to the manufacturer's instructions. Immunoblotting was performed, and samples probed for HIF1 $\alpha$ (Cell Signaling CST\# 36169), $\alpha$-tubulin (Sigma Cat\# T6199), and nuclear lamin B1 (Cell Signaling CST\# 12586).

Response to EGF stimulation was assessed by seeding $7.5 \times 10^{4} \mathrm{WT}$ or capns $1 \mathrm{KO}$ MTECs in $60 \mathrm{~mm}$ dishes overnight in complete IMEM. MTECs were washed once in PBS and changed to serum-free IMEM overnight, then stimulated with $3 \mathrm{~mL}$ of $50 \mathrm{ng} / \mathrm{mL}$ EGF (Thermo Fisher) prepared in serum-free IMEM for the indicated times. Cells were placed on ice and washed once with PBS containing $1 \mathrm{mM}$ sodium orthovanadate and lysed into RIPA as previously described. Immunoblotting was performed, and samples probed for EGFR (Cell Signaling CST\# 2232), P-EGFR (Y845) (Cell Signaling CST\# 2231), MEK (Cell Signaling CST\# 9122), P-MEK (S217/221) (Cell Signaling CST\# 9121), ERK (Cell Signaling CST\# 9102), and P-ERK (T202/Y204) (Cell Signaling CST\# 9101).

\section{Matrix metalloproteinase assay}

To assess the secretion of matrix metalloproteinase 2 and $9(\mathrm{MMP} 2 / 9), 7 \times 10^{5} \mathrm{WT}$ or capns $1 \mathrm{KO}$ MTECs were seeded overnight on $60 \mathrm{~mm}$ tissue culture dishes in complete IMEM, and the following day plates were washed twice with PBS and overlaid with $3 \mathrm{~mL}$ of serumfree IMEM. Cells were allowed to condition the medium for $48 \mathrm{~h}$ and gelatin zymography was performed as described by [72].

\section{Orthotopic tumor growth}

One $\times 10^{6} \mathrm{WT}$ or capns1 KO MTECs were suspended in $50 \mathrm{~mL}$ of $50 \%$ phosphate-buffered saline, and $50 \%$ growth factor reduced matrigel (VWR), and engrafted into the number four (abdominal) mammary gland of

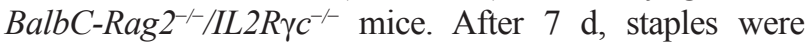
removed from surgical sites and tumor volumes assessed until endpoints. At endpoints, mice were euthanized, and tumors resected and lysed into RIPA buffer containing protease and phosphatase inhibitors (as described previously) for calpain immunoblotting analysis. Mice were housed at the Queen's University Animal Care Facility, and all procedures were carried out in accordance with the guidelines specified by the Canadian Council on Animal Care, with approval from the University Animal Care Committee.

\section{Reverse-phase protein microarray (RPPA)}

Cell lysates prepared from various tumor samples were printed using Aushon 2470 Arrayer (Aushon Biosystems). Validation of antibodies, staining, and analysis of array data was performed as described previously [29, 30].

\section{Abbreviations}

AKT: protein kinase B; CRE: causes recombination; EGF: epidermal growth factor; EGFR: EGF receptor; ERK: extracellular signal-regulated kinase; floxed: flanked by loxP recombination sites; GSK3 $\beta$ : glycogen synthase kinase 3 beta; HER2: human epidermal growth factor receptor 2; HIF 1 $\alpha$ : hypoxia-inducible factor 1 alpha; IRES: internal ribosome entry site; JNK: Jun N-terminal kinase; KO: knockout; MAPK: mitogen activated protein kinase; MARCKS: myristoylated alanine-rich C-kinase substrate; MEF: mouse embryonic fibroblasts; MEK: MAPK kinase; MMP: matrix metalloprotease; $M M T V$ LTR: mouse mammary tumor virus long terminal repeat; MRP2: multidrug resistance protein 2; MTEC: mammary tumor epithelial cell; MYC: myelocytomatosis viral oncogene; NEU: neuroblastoma oncogene; NIC: $M M T V$ NEU-IRES-CRE transgene; Pgp: P-glycoprotein; PI3K: phosphatidylinositol-3-kinase; PKC: protein kinase $\mathrm{C}$; PP2A: protein phosphatase 2A; STAT1: signal transducer and activator of transcription 1 .

\section{Author contributions}

J.M. carried out all experiments except for the RPPA analysis and wrote the manuscript. Y.G and C.H. assisted with mouse tumor studies and some biochemical analysis. W.J.M. produced the NIC mouse model and edited the manuscript. T.S.G. performed the RPPA analysis and edited the manuscript. P.A.G. conceived experiments and edited the manuscript.

\section{ACKNOWLEDGMENTS}

We are grateful to Changnian Shi for assistance with mouse tumor assessment, Matt Gordon and Jeff Mewburn 
for assistance with fluorescence microscopy, Charles Graham for access to a hypoxic incubator, and Bruce Elliott, Waheed Sangrar, David LeBrun, Kevin Ren, Stacy Grieve and Victoria Hoskin for assistance with tumor analysis and helpful discussions.

\section{CONFLICTS OF INTEREST}

The authors declare no conflicts of interest.

\section{FUNDING}

This work was supported by operating grants from the Canadian Institutes of Health Research-219806 and 219762, Canadian Cancer Society Research Institute and Canadian Breast Cancer Foundation-369404. W.J.M holds a CRC Chair in Molecular Oncology. J.M. was supported by a scholarship from the Terry Fox Foundation Training Program in Transdisciplinary Cancer Research in partnership with Canadian Institutes of Health Research-98285.

\section{REFERENCES}

1. Campbell RL, Davies PL. Structure-function relationships in calpains. Biochem J. 2012; 447:335-51.

2. Goll DE, Thompson VF, Li H, Wei W, Cong J. The calpain system. Physiol Rev. 2003; 83:731-801.

3. Suzuki K, Sorimachi H, Yoshizawa T, Kinbara K, Ishiura S. Calpain: novel family members, activation, and physiologic function. Biol Chem Hoppe Seyler. 1995; 376:523-9.

4. Ono Y, Saido TC, Sorimachi H. Calpain research for drug discovery: challenges and potential. Nat Rev Drug Discov. 2016; 15:854-76.

5. Arthur JS, Elce JS, Hegadorn C, Williams K, Greer PA. Disruption of the murine calpain small subunit gene, Capn4: calpain is essential for embryonic development but not for cell growth and division. Mol Cell Biol. 2000; 20:4474-81.

6. Tan Y, Dourdin N, Wu C, De Veyra T, Elce JS, Greer PA. Conditional disruption of ubiquitous calpains in the mouse. Genesis. 2006; 44:297-303.

7. Liu Z, Cao J, Gao X, Ma Q, Ren J, Xue Y. GPS-CCD: a novel computational program for the prediction of calpain cleavage sites. PLoS One. 2011; 6:e19001.

8. Storr SJ, Carragher NO, Frame MC, Parr T, Martin SG. The calpain system and cancer. Nat Rev Cancer. 2011; 11:364-74.

9. Ho WC, Pikor L, Gao Y, Elliott BE, Greer PA. Calpain 2 regulates Akt-FoxO-p27(Kip1) protein signaling pathway in mammary carcinoma. J Biol Chem. 2012; 287:15458-65.

10. Tan Y, Dourdin N, Wu C, De Veyra T, Elce JS, Greer PA. Ubiquitous calpains promote caspase-12 and JNK activation during endoplasmic reticulum stress-induced apoptosis. J Biol Chem. 2006; 281:16016-24.
11. Tan Y, Wu C, De Veyra T, Greer PA. Ubiquitous calpains promote both apoptosis and survival signals in response to different cell death stimuli. J Biol Chem. 2006; 281:17689-98.

12. Janossy J, Ubezio P, Apati A, Magocsi M, Tompa P, Friedrich P. Calpain as a multi-site regulator of cell cycle. Biochem Pharmacol. 2004; 67:1513-21.

13. Libertini SJ, Robinson BS, Dhillon NK, Glick D, George M, Dandekar S, Gregg JP, Sawai E, Mudryj M. Cyclin E both regulates and is regulated by calpain 2 , a protease associated with metastatic breast cancer phenotype. Cancer Res. 2005; 65:10700-8.

14. Wang XD, Rosales JL, Magliocco A, Gnanakumar R, Lee KY. Cyclin E in breast tumors is cleaved into its low molecular weight forms by calpain. Oncogene. 2003; 22:769-74.

15. Dourdin N, Bhatt AK, Dutt P, Greer PA, Arthur JS, Elce JS, Huttenlocher A. Reduced cell migration and disruption of the actin cytoskeleton in calpain-deficient embryonic fibroblasts. J Biol Chem. 2001; 276:48382-8.

16. Franco S, Perrin B, Huttenlocher A. Isoform specific function of calpain 2 in regulating membrane protrusion. Exp Cell Res. 2004; 299:179-87.

17. Postovit LM, Dutt P, Dourdin N, Park M, Greer PA, Graham $\mathrm{CH}$, Elce JS. Calpain is required for MMP-2 and u-PA expression in SV40 large T-antigen-immortalized cells. Biochem Biophys Res Commun. 2002; 297:294-301.

18. Franco SJ, Rodgers MA, Perrin BJ, Han J, Bennin DA, Critchley DR, Huttenlocher A. Calpain-mediated proteolysis of talin regulates adhesion dynamics. Nat Cell Biol. 2004; 6:977-83.

19. Kulkarni S, Reddy KB, Esteva FJ, Moore HC, Budd GT, Tubbs RR. Calpain regulates sensitivity to trastuzumab and survival in HER2-positive breast cancer. Oncogene. 2010; 29:1339-50.

20. Conacci-Sorrell M, Ngouenet C, Eisenman RN. Myc-nick: a cytoplasmic cleavage product of Myc that promotes alphatubulin acetylation and cell differentiation. Cell. 2010; 142:480-93.

21. Storr SJ, Lee KW, Woolston CM, Safuan S, Green AR, Macmillan RD, Benhasouna A, Parr T, Ellis IO, Martin SG. Calpain system protein expression in basal-like and triple-negative invasive breast cancer. Ann Oncol. 2012; 23:2289-96.

22. Storr SJ, Woolston CM, Barros FF, Green AR, Shehata M, Chan SY, Ellis IO, Martin SG. Calpain-1 expression is associated with relapse-free survival in breast cancer patients treated with trastuzumab following adjuvant chemotherapy. Int J Cancer. 2011; 129:1773-80.

23. Storr SJ, Safuan S, Woolston CM, Abdel-Fatah T, Deen S, Chan SY, Martin SG. Calpain-2 expression is associated with response to platinum based chemotherapy, progressionfree and overall survival in ovarian cancer. J Cell Mol Med. $2012 ; 16: 2422-8$. 
24. Scaltriti M, Rojo F, Ocana A, Anido J, Guzman M, Cortes J, Di Cosimo S, Matias-Guiu X, Ramon y Cajal S, Arribas J, Baselga J. Expression of p95HER2, a truncated form of the HER2 receptor, and response to anti-HER2 therapies in breast cancer. J Natl Cancer Inst. 2007; 99:628-38.

25. Grieve S, Gao Y, Hall C, Hu J, Greer PA. Calpain Genetic Disruption and HSP90 Inhibition Combine To Attenuate Mammary Tumorigenesis. Mol Cell Biol. 2016; 36:2078-88.

26. Graham-Siegenthaler K, Gauthier S, Davies PL, Elce JS. Active recombinant rat calpain II. Bacterially produced large and small subunits associate both in vivo and in vitro. J Biol Chem. 1994; 269:30457-60.

27. Meyer SL, Bozyczko-Coyne D, Mallya SK, Spais CM, Bihovsky R, Kaywooya JK, Lang DM, Scott RW, Siman R. Biologically active monomeric and heterodimeric recombinant human calpain I produced using the baculovirus expression system. Biochem J. 1996; 314:511-9.

28. Ursini-Siegel J, Hardy WR, Zuo D, Lam SH, SanguinGendreau V, Cardiff RD, Pawson T, Muller WJ. ShcA signalling is essential for tumour progression in mouse models of human breast cancer. EMBO J. 2008; 27:910-20.

29. Luckert K, Gujral TS, Chan M, Sevecka M, Joos TO, Sorger PK, Macbeath G, Potz O. A dual array-based approach to assess the abundance and posttranslational modification state of signaling proteins. Sci Signal. 2012; 5:pl1.

30. Gujral TS, Karp RL, Finski A, Chan M, Schwartz PE, MacBeath G, Sorger P. Profiling phospho-signaling networks in breast cancer using reverse-phase protein arrays. Oncogene. 2013; 32:3470-6.

31. Muller WJ, Sinn E, Pattengale PK, Wallace R, Leder P. Single-step induction of mammary adenocarcinoma in transgenic mice bearing the activated c-neu oncogene. Cell. 1988; 54:105-15.

32. Huttenlocher A, Palecek SP, Lu Q, Zhang W, Mellgren RL, Lauffenburger DA, Ginsberg MH, Horwitz AF. Regulation of cell migration by the calcium-dependent protease calpain. J Biol Chem. 1997; 272:32719-22.

33. Robidoux A, Tang G, Rastogi P, Geyer CE Jr, Azar CA, Atkins JN, Fehrenbacher L, Bear HD, Baez-Diaz L, Sarwar S, Margolese RG, Farrar WB, Brufsky AM, et al. Lapatinib as a component of neoadjuvant therapy for HER2-positive operable breast cancer (NSABP protocol B-41): an openlabel, randomised phase 3 trial. Lancet Oncol. 2013; 14:1183-92.

34. Burstein HJ, Storniolo AM, Franco S, Forster J, Stein S, Rubin S, Salazar VM, Blackwell KL. A phase II study of lapatinib monotherapy in chemotherapy-refractory HER2positive and HER2-negative advanced or metastatic breast cancer. Ann Oncol. 2008; 19:1068-74.

35. Geyer CE, Forster J, Lindquist D, Chan S, Romieu CG, Pienkowski T, Jagiello-Gruszfeld A, Crown J, Chan A, Kaufman B, Skarlos D, Campone M, Davidson N, et al.
Lapatinib plus capecitabine for HER2-positive advanced breast cancer. N Engl J Med. 2006; 355:2733-43.

36. Jeon KH, Yu HV, Kwon Y. Hyperactivated m-calpain affects acquisition of doxorubicin resistance in breast cancer cells. Biochim Biophys Acta. 2018; 1862:1126-1133.

37. Semenza GL. HIF-1 and tumor progression: pathophysiology and therapeutics. Trends Mol Med. 2002; 8:S62-7.

38. Tug S, Delos Reyes B, Fandrey J, Berchner-Pfannschmidt U. Non-hypoxic activation of the negative regulatory feedback loop of prolyl-hydroxylase oxygen sensors. Biochem Biophys Res Commun. 2009; 384:519-23.

39. Zheng X, Zhou AX, Rouhi P, Uramoto H, Boren J, Cao Y, Pereira T, Akyurek LM, Poellinger L. Hypoxia-induced and calpain-dependent cleavage of filamin A regulates the hypoxic response. Proc Natl Acad Sci U S A. 2014; 111:2560-5.

40. Jones JL, Glynn P, Walker RA. Expression of MMP-2 and MMP-9, their inhibitors, and the activator MT1-MMP in primary breast carcinomas. J Pathol. 1999; 189:161-8.

41. Li HC, Cao DC, Liu Y, Hou YF, Wu J, Lu JS, Di GH, Liu G, Li FM, Ou ZL, Jie C, Shen ZZ, Shao ZM. Prognostic value of matrix metalloproteinases (MMP-2 and MMP-9) in patients with lymph node-negative breast carcinoma. Breast Cancer Res Treat. 2004; 88:75-85.

42. Somiari SB, Somiari RI, Heckman CM, Olsen CH, Jordan RM, Russell SJ, Shriver CD. Circulating MMP2 and MMP9 in breast cancer-potential role in classification of patients into low risk, high risk, benign disease and breast cancer categories. Int J Cancer. 2006; 119:1403-11.

43. Walker RA, Dearing SJ. Expression of epidermal growth factor receptor mRNA and protein in primary breast carcinomas. Breast Cancer Res Treat. 1999; 53:167-76.

44. Yersal O, Barutca S. Biological subtypes of breast cancer: Prognostic and therapeutic implications. World J Clin Oncol. 2014; 5:412-24.

45. Gelmon KA, Boyle FM, Kaufman B, Huntsman DG, Manikhas A, Di Leo A, Martin M, Schwartzberg LS, Lemieux J, Aparicio S, Shepherd LE, Dent S, Ellard SL, et al. Lapatinib or Trastuzumab Plus Taxane Therapy for Human Epidermal Growth Factor Receptor 2-Positive Advanced Breast Cancer: Final Results of NCIC CTG MA.31. J Clin Oncol. 2015; 33:1574-83.

46. Storr SJ, Thompson N, Pu X, Zhang Y, Martin SG. Calpain in Breast Cancer: Role in Disease Progression and Treatment Response. Pathobiology. 2015; 82:133-41.

47. Kulkarni S, Saju L, Farver C, Tubbs R. Calpain4 is required for activation of HER2 in breast cancer cells exposed to trastuzumab and its suppression decreases survival and enhances response. Int J Cancer. 2012; 131:2420-32.

48. Mancinelli R, Carpino G, Petrungaro S, Mammola CL, Tomaipitinca L, Filippini A, Facchiano A, Ziparo E, Giampietri C. Multifaceted Roles of GSK-3 in Cancer and Autophagy-Related Diseases. Oxid Med Cell Longev. 2017; 2017:4629495. 
49. Bertoli C, Copetti T, Lam EW, Demarchi F, Schneider C. Calpain small-1 modulates Akt/FoxO3A signaling and apoptosis through PP2A. Oncogene. 2009; 28:721-33.

50. Huang C, Jacobson K, Schaller MD. MAP kinases and cell migration. J Cell Sci. 2004; 117:4619-28.

51. Hu J, Adler K, Farah CA, Hastings MH, Sossin WS, Schacher S. Cell-Specific PKM Isoforms Contribute to the Maintenance of Different Forms of Persistent Long-Term Synaptic Plasticity. J Neurosci. 2017; 37:2746-63.

52. Wallace JA, Pitarresi JR, Sharma N, Palettas M, Cuitino MC, Sizemore ST, Yu L, Sanderlin A, Rosol TJ, Mehta KD, Sizemore GM, Ostrowski MC. Protein kinase C Beta in the tumor microenvironment promotes mammary tumorigenesis. Front Oncol. 2014; 4:87.

53. Chen $\mathrm{CH}$, Cheng CT, Yuan Y, Zhai J, Arif M, Fong LW, Wu R, Ann DK. Elevated MARCKS phosphorylation contributes to unresponsiveness of breast cancer to paclitaxel treatment. Oncotarget. 2015; 6:15194-208. https://doi.org/10.18632/oncotarget.3827.

54. Stephanou A, Latchman DS. STAT-1: a novel regulator of apoptosis. Int J Exp Pathol. 2003; 84:239-44.

55. Kachroo P, Lee MH, Zhang L, Baratelli F, Lee G, Srivastava MK, Wang G, Walser TC, Krysan K, Sharma S, Dubinett SM, Lee JM. IL-27 inhibits epithelial-mesenchymal transition and angiogenic factor production in a STAT1dominant pathway in human non-small cell lung cancer. J Exp Clin Cancer Res. 2013; 32:97.

56. Hynes NE, Lane HA. ERBB receptors and cancer: the complexity of targeted inhibitors. Nat Rev Cancer. 2005; 5:341-54.

57. Gregoriou M, Willis AC, Pearson MA, Crawford C. The calpain cleavage sites in the epidermal growth factor receptor kinase domain. Eur J Biochem. 1994; 223:455-64.

58. Arribas J, Baselga J, Pedersen K, Parra-Palau JL. p95HER2 and breast cancer. Cancer Res. 2011; 71:1515-9.

59. Nagata Y, Lan KH, Zhou X, Tan M, Esteva FJ, Sahin AA, Klos KS, Li P, Monia BP, Nguyen NT, Hortobagyi GN, Hung MC, Yu D. PTEN activation contributes to tumor inhibition by trastuzumab, and loss of PTEN predicts trastuzumab resistance in patients. Cancer Cell. 2004; 6:117-27.

60. Clark AS, West K, Streicher S, Dennis PA. Constitutive and inducible Akt activity promotes resistance to chemotherapy, trastuzumab, or tamoxifen in breast cancer cells. Mol Cancer Ther. 2002; 1:707-17.

61. Sangrar W, Shi C, Mullins G, LeBrun D, Ingalls B, Greer PA. Amplified Ras-MAPK signal states correlate with accelerated EGFR internalization, cytostasis and delayed HER2 tumor onset in Fer-deficient model systems. Oncogene. 2015; 34:4109-17.
62. Blagosklonny MV. Cell senescence and hypermitogenic arrest. EMBO Rep. 2003; 4:358-62.

63. Ebisuya M, Kondoh K, Nishida E. The duration, magnitude and compartmentalization of ERK MAP kinase activity: mechanisms for providing signaling specificity. J Cell Sci. 2005; 118:2997-3002.

64. Marshall CJ. Specificity of receptor tyrosine kinase signaling: transient versus sustained extracellular signalregulated kinase activation. Cell. 1995; 80:179-85.

65. Ewald AJ. Pulling cells out of tumours. Nat Cell Biol. 2017; 19:147-9.

66. Martinez-Outschoorn UE, Trimmer C, Lin Z, WhitakerMenezes D, Chiavarina B, Zhou J, Wang C, Pavlides S, Martinez-Cantarin MP, Capozza F, Witkiewicz AK, Flomenberg N, Howell A, et al. Autophagy in cancer associated fibroblasts promotes tumor cell survival: Role of hypoxia, HIF1 induction and NFkappaB activation in the tumor stromal microenvironment. Cell Cycle. 2010; 9:3515-33.

67. Lee $\mathrm{CW}$, Lin $\mathrm{CC}$, Lin $\mathrm{WN}$, Liang $\mathrm{KC}$, Luo $\mathrm{SF}, \mathrm{Wu}$ CB, Wang SW, Yang CM. TNF-alpha induces MMP-9 expression via activation of Src/EGFR, PDGFR/PI3K/ Akt cascade and promotion of NF-kappaB/p300 binding in human tracheal smooth muscle cells. Am J Physiol Lung Cell Mol Physiol. 2007; 292:L799-812.

68. Kwak HI, Kang H, Dave JM, Mendoza EA, Su SC, Maxwell SA, Bayless KJ. Calpain-mediated vimentin cleavage occurs upstream of MT1-MMP membrane translocation to facilitate endothelial sprout initiation. Angiogenesis. 2012; 15:287-303.

69. Yu Q, Sicinska E, Geng Y, Ahnstrom M, Zagozdzon A, Kong Y, Gardner H, Kiyokawa H, Harris LN, Stal O, Sicinski P. Requirement for CDK4 kinase function in breast cancer. Cancer Cell. 2006; 9:23-32.

70. Croall DE, Moffett K, Hatch H. Casein zymography of calpains using a 4-(2-hydroxyethyl)-1-piperazineethanesulfonic acidimidazole buffer. Anal Biochem. 2002; 304:129-32.

71. Samis JA, Back DW, Graham EJ, DeLuca CI, Elce JS. Constitutive expression of calpain II in the rat uterus during pregnancy and involution. Biochem J. 1991; 276:293-9.

72. Toth M, Sohail A, Fridman R. Assessment of gelatinases (MMP-2 and MMP-9) by gelatin zymography. Methods Mol Biol. 2012; 878:121-35. 